\title{
Policies and Consumption-Based Carbon Emissions from a Top-Down and a Bottom-Up Perspective
}

\author{
Kirsten S. Wiebe ${ }^{1,2}$, Simon Gandy ${ }^{3}$, Christian Lutz ${ }^{1^{*}}$ \\ ${ }^{1}$ Institute of Economic Structures Research (GWS mbH), Osnabrück, Germany \\ ${ }^{2}$ UNU-MERIT, Maastricht, The Netherlands \\ ${ }^{3}$ Ricardo Energy \& Environment, Harwell, UK \\ Email: *lutz@gws-os.de
}

Received 19 February 2016; accepted 13 March 2016; published 16 March 2016

Copyright (C) 2016 by authors and Scientific Research Publishing Inc.

This work is licensed under the Creative Commons Attribution International License (CC BY). http://creativecommons.org/licenses/by/4.0/

\section{(c) (i) Open Access}

\section{Abstract}

Two major approaches for calculating consumption-based carbon emissions can be distinguished: top-down approaches, in the form of multi-regional input-output (MRIO) models, and bottom-up approaches, in the form of life cycle assessment (LCA). Both approaches have pros and cons and are very data-intensive. Several MRIO databases have been developed and published over the past years. These databases, which have been refined and validated, will be used for policy analysis. As LCA is usually only applied to very specific products and product groups, analysis is limited and many products have not yet been looked at. This paper makes use of both a top-down and bottomup approach to calculate the impacts of different policy measures on the development of consumption-based carbon emissions in the EU28 and on emissions elsewhere in the world. The policy examples used are the EU's $\mathrm{CO}_{2}$ in Cars Regulations and the South African renewable energy initiative. The results from the top-down approach are then compared with those from the bottomup approach. Both bottom-up and top-down approaches use the same underlying assumptions regarding the impacts, but due to the very different nature of the methodologies, differences in the results are observed, though sign and scope of the results are the same for the two cases. Part of the deviations can be explained by differences in methodology and scenario design due to these differences. It can be concluded that bottom-up and top-down approaches can and need to be applied to different policies and are generally complementary.

\section{Keywords}

Carbon Emissions, Life Cycle Assessment, Multi-Regional Input-Output Analysis, Car Industry, Renewable Energy

\footnotetext{
"Corresponding author.
} 


\section{Introduction}

The approaches for calculating consumption-based carbon emissions can be divided into two broad categories: top-down approaches, in the form of multi-regional input-output (MRIO) models, and bottom-up approaches, in the form of process analysis commonly known as life cycle assessment (LCA). A review on other possible methodologies, e.g. material flow analysis, and further refinements or alterations of the two main approaches, e.g. physical input-output models, can be found in [1]. Both LCA and MRIO approaches have their pros and cons. They differ with respect to their level of detail, system boundaries and spatial and temporal resolution. While LCA usually looks at individual products or services and requires either substantial data collection or the use of available LCA databases, input-output models mostly consider readily available data (provided by national statistical offices or international institutions) on the aggregated industry or product group level. These different levels of detail have an immediate impact on system boundaries: the boundary of an LCA is usually the individual product and a few stages in its production chain [2]. In contrast, global MRIO models consider all industries in all countries around the globe (though that does not necessarily mean that all countries are modelled individually; in most models, some countries are aggregated into regions). Hence, the system boundary of MRIO analysis is much wider than the system boundary of LCA, but MRIO models use average industry/product group data, so that the true impact of a certain product belonging to that industry/product group may be hidden. Various forms of hybrid approaches have been developed recently [3]-[6].

The paper at hand uses both methodologies to analyze the impact of two different policy measures on EU28 consumption-based carbon accounts. Both bottom-up and top-down approaches use the same underlying assumptions regarding the policy impacts, but due to the very different nature of the methods, differences in the results have been found and need to be explained. Carbon policies in a country or a group of countries will also have impacts on emissions in other parts of the world through global trade and production chains. A major objective of the paper is to show these impacts and what can be expected from a combination of both approaches. In the future this kind of accounting may become important to define and understand the different impacts of additional national carbon policies to meet the ambitious climate targets of the Paris agreement from December 2015. Though focusing on carbon, both case studies look into resource use and policy and could be extended from carbon emissions and underlying fossil fuel consumption to other emissions and resources.

The paper is structured as follows: in the methods Section 2 short individual overviews on LCA and MRIO analysis are presented. Further, the possible combination of top-down and bottom-up approaches in the form of hybrid LCA analysis is briefly discussed. Finally the GRAM model applied as MRIO is briefly introduced and necessary additions for the car case study are presented. In Section 3 the two case studies, the policy examples of the $\mathrm{EU} \mathrm{CO}_{2}$ in cars regulation and the South African renewable energy procurement programs and its impact on aluminium production and related energy consumption are introduced. Results of the bottom-up and the topdown analysis are compared after showing the individual results. The final Section 4 gives both methodological and policy conclusions.

\section{Methods}

\subsection{Bottom-Up Methodologies}

LCA is the systematic analysis of the environmental impacts of products, services, processes and policies (hereafter simply called "products”) during their entire life cycle (cradle to grave), including production, use and disposal phases. LCA is used to understand and quantify the environmental impacts of products; it enables the comparison of alternatives to identify the best option based on environmental impact. It is widely used to improve products at the design stage; the largest environmental impact of a product can be identified so that its design can be improved. In improving a product's design, an LCA approach will ensure that its environmental burdens are not just shifted in the product system between environmental indicators but improved overall [7]. The International Organisation for Standardisation [8] provides guidelines for conducting a process-based LCA within the series ISO 14040 and 14044. While the ISO standards provide a systematic framework, data requirements, analysis boundaries and assessment methods are not specified.

The bottom-up approach divides the life cycle of a product or process into distinct life cycle stages. The stages covered by LCA include raw material acquisition, material processing, manufacture and assembly, use and service, and recovery and disposal. Each of these stages can include material and energy inputs as well as waste 
(liquid, solid, gaseous) outputs.

Material and energy requirements are determined for each of the stages, the outputs are determined and the total for the whole life cycle is estimated in the Life Cycle Inventory (LCI). Impact factors are then used to scale each inventory item (for example, the global warming impact of producing a raw material will be given in units of $\mathrm{kg} \mathrm{CO}$-equivalent per $\mathrm{kg}$ of raw material), and the contributions summed to determine the overall Life Cycle Impact Assessment, which is often determined for a number of environmental impacts. This approach for LCA was introduced in the 1960s for cleaner production and has had broad applications in industry and academia. It has been used widely in the analysis of power generation fuel cycles such as coal, gas, wind, solar, etc. [9].

\subsection{Top-Down Methodologies}

Multi-regional or inter-country input-output (MRIO) models are applied economic research and analysis tools. Leontief published an environmental economic extension of input-output models as early as 1970. Using environmentally extended MRIO models, it is possible to identify the carbon emissions embodied in international trade and analyze all direct and indirect linkages between consumption, value added along the production chains and emissions associated with production and trade in different regions of the world. "For consumption-based accounting of greenhouse gas emissions in global carbon footprint analyses, MRIO has already become the norm.” [10], p. 1983. Different publications using MRIO focus on footprints of nations (e.g. [4], [6]). Still, there have only been very few policy specific applications of global MRIO models so far. Some of these were initiated by the UK Department for Environment, Food and Rural Affairs (Defra), which has now included indicators relating to consumption-based emission accounts in the headline indicators for sustainability [11].

Different MRIO databases have been published in recent years. These include models based on GTAP (e.g. [12]); EORA [13]; OECD [14]-[16]; EXIOBASE [17] and WIOD [18] data. The models not only differ because of differences in the datasets (geographical, time and sectoral coverage), but also due to different measurement methodologies or underlying assumptions [19]. Still, the qualitative outcomes of all models with regard to regional distribution of consumption-based emissions are the same as analyzed by [20]. Even though the details differ, the underlying mathematical model is exactly the same and described in detail in the literature [13] [17] [18] [21]. A technical description of the MRIO used in this paper, GRAM, can be found in [15]. It is briefly presented in 2.4 .

\subsection{Hybrid Analysis}

To overcome the greatest limitations of top-down and bottom-up analyses, discussed in detail in [6], hybrid IO-process-based methodologies were developed (see [22] for a description of the historical development, and [23], for a description of hybridization of MRIOs). Hybrid analysis combines IO analysis and process analysis with the aim of minimizing their inherent errors by maximizing the overall completeness and accuracy [3], [23]-[28]. Most of these studies deal with individual products in one country (e.g. [23] [29]-[31]). Only recently this type of analysis was also applied at the meso/macro-level. However this was limited to selected industrial sectors in Taiwan [32].

Rather than applying a hybrid analysis, our research suggests that for certain cases the bottom-up LCA methodology is more applicable, while for other applications the results generated by an MRIO analysis are more useful. This will be shown in the next sections using two case study examples.

\subsection{GRAM Model for Top-Down Analysis}

The Global Resource Accounting Model (GRAM) is an MRIO system covering 48 industries in 62 countries and the rest of the world for the years between 1995 and 2011 [15] [16]. The system is based on input-output tables (IOTs) and bilateral trade data of the OECD and data on $\mathrm{CO}_{2}$ emissions from fuel combustion of the IEA. The OECD IOTs are not available for every year. The data for the missing years has been interpolated and scaled to the UN System of National Accounts aggregates data.

For modelling the effect of the diffusion of new technologies such as renewable energy or hybrid and electric cars, the economic structure or some industries need to be changed. This is described in detail for the case of solar and wind power in [33]. A diffusion of these technologies affects the input structure of three industries, electrical machinery and apparatus, which produces solar photovoltaic modules, the machinery and equipment in- 
dustry, which produces wind turbines and the electricity industry, as fewer fossil fuels are needed. When fewer fossil fuels are used by the electricity industry, the $\mathrm{CO}_{2}$ intensity of the electricity industry is reduced. In addition, investment (gross fixed capital formation in final demand) changes as more and more PV modules and wind turbines are installed.

For the car case study, presented in 3.2 similar changes to the input-output system need to be explained. The product "car" is part of industry " 21 Motor vehicles, trailers \& semi-trailers". Introducing new car technologies affects three GRAM variables: input structure $A$, final demand $Y$, and emission intensity $e$, see Figure 1 . The input structure is affected because electric cars need electric motors and batteries and no internal combustion engines. The structure of final demand changes, because electric cars are more expensive and final users use more electricity and less petroleum products. The emission intensity of the transport sector changes, because fewer cars use petroleum products and more cars use electricity to provide energy for the motor (see [34] for more detail). This results in changes (as displayed in Figure 1) of inputs from six industries in GRAM. These industries are among those in which are the highest emissions embedded in EU motor vehicle, trailer and semitrailer demand.

The change from internal combustion engine (ICE) vehicles to hybrid motor vehicles (HEVs) or battery electric motor vehicles (BEVs) affects the input coefficient structure (variable $A$ ) of two industries in GRAM (see Figure 1): 21 motor vehicles, trailers \& semi-trailers, reflecting the changing input structure when building motor vehicles and thus relating to emissions embedded in upstream production including imports, and 33 land transport; transport via pipelines, reflecting the changing use of fuels-electricity instead of petroleum products and thus relating to in-use emissions, i.e. petroleum products and electricity.

The motor vehicle industry needs fewer internal combustion engines and parts that are necessary for these engines as well as fewer rubber and plastics products, but more batteries and other electrical equipment used to build an electric motor. Sugawara and Shibusawa [35], using the Japanese input-output table, are able to differentiate between the industries "motor vehicles", "motor vehicle parts" and "internal combustion engine". The first of these is the industry that actually produces the cars, while the other two provide inputs for ICE vehicles. Therefore the inputs of these two industries into "motor vehicles" decreases, while the inputs of industries "other electronics and electronic products" (which is assumed to produce the batteries) and "heavy electrical equipment" (which is assumed to produce the electrical motors) increase.

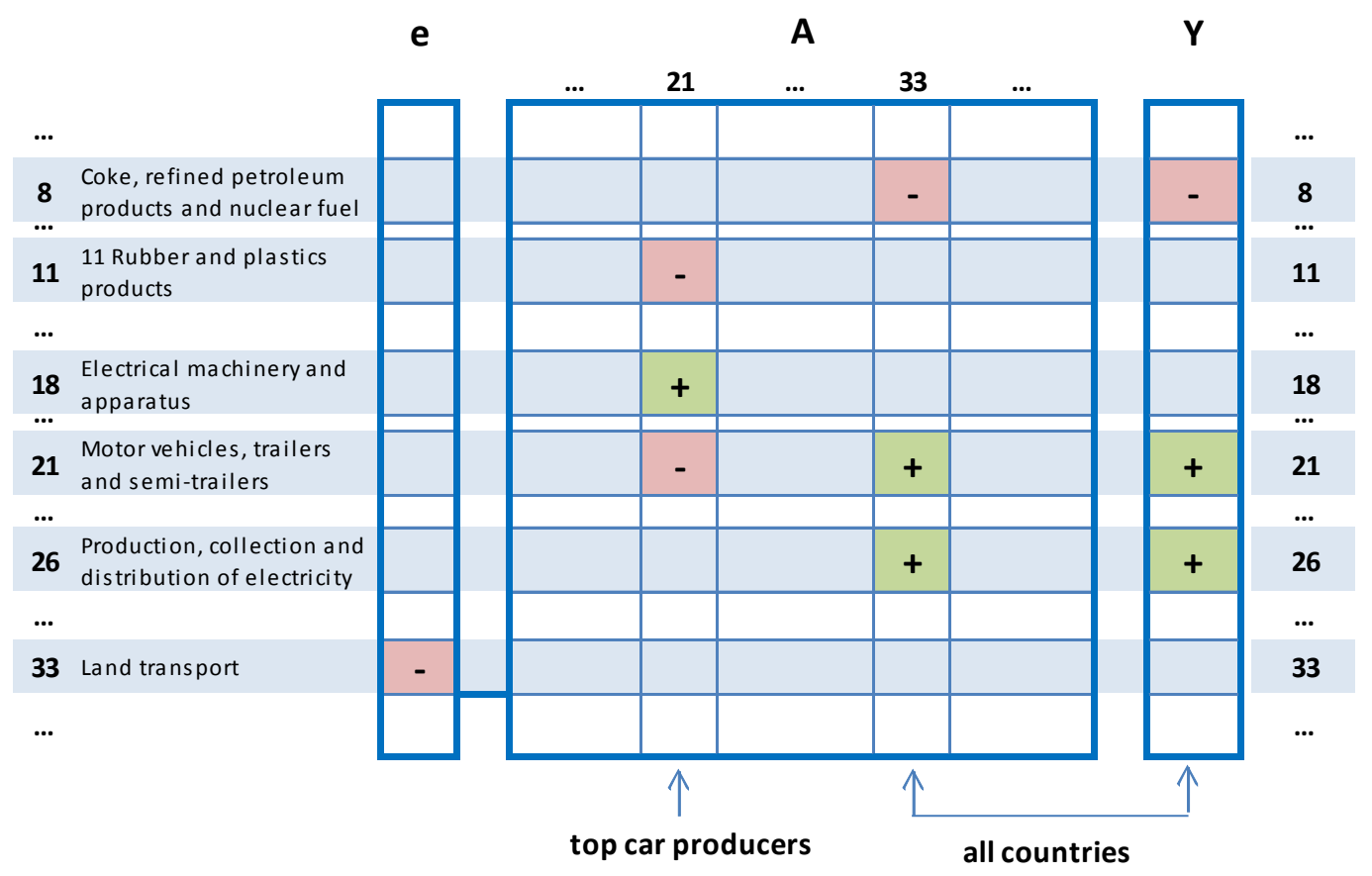

Figure 1. Changes in GRAM variables. This figure shows the MRIO variables emission intensities e, intermediate coefficient matrix A, and final demand y in tabular form. Six sectors, highlighted in blue, are affected by the changing structure of the car industry. The direction of the change in the corresponding variables is marked by a + or - in the entry of the tables. 
In the given ISIC Rev. 3 industry classification in GRAM, industry "21 Motor vehicles, trailers \& semi-trailers” includes all of "motor vehicles", "motor vehicle parts" and "internal combustion engine”, and "other electronics and electronic products" and "heavy electrical equipment" are part of "18 Electrical machinery \& apparatus, nec.”. Still, it is possible to do a similar simulation as has been done in [35], by changing the input coefficients of " 21 Motor vehicles, trailers \& semi-trailers" as displayed in Table 1.

The new input coefficients are calculated as a weighted average of the original input coefficients and the input coefficients for the new technologies. The weights correspond to the share of the different car technologies in total car manufacturing. For the simple scenario calculated here, we assume the following shares of electric cars in total car manufacturing based on the "Current Policy Initiatives" Scenario from the bottom-up case study for the year 2030 and corresponding shares in the car fleet, see Table 2. The shares in the car fleet indicate the changing demand for energy sources—diminishing for petroleum products and increasing for electricity.

Table 1. Changes in input structure of " 21 Motor vehicles, trailers \& semi-trailers” for electric cars and "33 Land transport, transport via pipelines” and final demand.

\begin{tabular}{ccc}
\hline & $\begin{array}{c}\text { 21 Motor vehicles, } \\
\text { trailers \& semi-trailers }\end{array}$ & $\begin{array}{c}\text { 33 Land transport, transport via pipelines } \\
\text { Final demand }\end{array}$ \\
\hline 8 Coke, refined petroleum products and nuclear fuel & & $-100 \%$ \\
11 Rubber and plastics products & $-0.035^{\mathrm{a}}$ & $+4 \%^{\mathrm{d}}$ \\
18 Electrical machinery \& apparatus, nec & $+0.175^{\mathrm{b}}$ & $-0.10^{\mathrm{c}}$ \\
21 Motor vehicles, trailers \& semi-trailers &
\end{tabular}

26 Production, collection and distribution of electricity

increase in electricity $=1 / 3$ decrease in oil use

33 Land transport

All changes absolute

All changes relative

${ }^{\mathrm{a}}(0.00[34]+-0.07[37]) / 2=-0.035,{ }^{\mathrm{b}}(0.20[34]+0.15[37]) / 2=+0.175,{ }^{\mathrm{c}}(-0.10[34]+-0.105[37]) / 2=-0.10,{ }^{\mathrm{d}}$ which is the percentage change in inputs in 21. The numbers used here are estimated based on [36], [37] as used in [35].

Table 2. Share of car technologies in production and car fleet based on CPI scenario of the bottom-up case study.

\begin{tabular}{|c|c|c|c|c|c|c|c|c|}
\hline \multirow{2}{*}{ Share in } & Production & Car fleet & Production & Car fleet & Production & Car fleet & Production & Car fleet \\
\hline & \multicolumn{2}{|c|}{$\mathrm{EU}$} & \multicolumn{2}{|c|}{ non-EU Europe } & \multicolumn{2}{|c|}{ US/CA/MX } & \multicolumn{2}{|c|}{ Australia } \\
\hline ICE & $88 \%$ & $91 \%$ & $95 \%$ & $97 \%$ & $90 \%$ & $92 \%$ & $91 \%$ & $94 \%$ \\
\hline HEV & $12 \%$ & $9 \%$ & $5 \%$ & $3 \%$ & $7 \%$ & $6 \%$ & $9 \%$ & $6 \%$ \\
\hline PHEV & $0 \%$ & $0 \%$ & $0 \%$ & $0 \%$ & $2 \%$ & $1 \%$ & $0 \%$ & $0 \%$ \\
\hline $\mathrm{BEV}$ & $0 \%$ & $0 \%$ & $0 \%$ & $0 \%$ & $1 \%$ & $0 \%$ & $0 \%$ & $0 \%$ \\
\hline FCEV & $0 \%$ & $0 \%$ & $0 \%$ & $0 \%$ & $0 \%$ & $0 \%$ & $0 \%$ & $0 \%$ \\
\hline Petro fuel & $94 \%$ & $96 \%$ & $98 \%$ & $99 \%$ & $95 \%$ & $96 \%$ & $96 \%$ & $97 \%$ \\
\hline Electricity & $6 \%$ & $4 \%$ & $3 \%$ & $1 \%$ & $6 \%$ & $4 \%$ & $5 \%$ & $3 \%$ \\
\hline \multirow{2}{*}{ Share in } & Production & Car fleet & Production & Car fleet & Production & Car fleet & Production & Car fleet \\
\hline & \multicolumn{2}{|c|}{ BR/LAC } & \multicolumn{2}{|c|}{ Russia } & \multicolumn{2}{|c|}{ India/MENA } & \multicolumn{2}{|c|}{ China } \\
\hline ICE & $99 \%$ & $99 \%$ & $96 \%$ & $98 \%$ & $94 \%$ & $96 \%$ & $89 \%$ & $93 \%$ \\
\hline HEV & $1 \%$ & $1 \%$ & $4 \%$ & $2 \%$ & $6 \%$ & $4 \%$ & $9 \%$ & $6 \%$ \\
\hline PHEV & $0 \%$ & $0 \%$ & $0 \%$ & $0 \%$ & $0 \%$ & $0 \%$ & $2 \%$ & $1 \%$ \\
\hline BEV & $0 \%$ & $0 \%$ & $0 \%$ & $0 \%$ & $0 \%$ & $0 \%$ & $0 \%$ & $0 \%$ \\
\hline FCEV & $0 \%$ & $0 \%$ & $0 \%$ & $0 \%$ & $0 \%$ & $0 \%$ & $0 \%$ & $0 \%$ \\
\hline Petro fuel & $99.5 \%$ & $99.5 \%$ & $98 \%$ & $99 \%$ & $97 \%$ & $98 \%$ & $95 \%$ & $96 \%$ \\
\hline Electricity & $0.5 \%$ & $0.5 \%$ & $2 \%$ & $1 \%$ & $3 \%$ & $2 \%$ & $6 \%$ & $4 \%$ \\
\hline
\end{tabular}


We further assume that electric cars are manufactured in the eight countries with existing production capacities for electric vehicles: Japan, US, France, UK, Korea, Spain, China, Germany. This excludes other countries with high shares in global car production, such as India, Brazil and Mexico

These production numbers need to be complemented with user penetration rates in the car fleet (Columns "car fleet" in Table 2) to be able to change both the inputs into road transport industry (electricity versus petroleum products) and the direct emission intensity of the transport sector itself as fewer cars run on petroleum products and more on electricity as described below. The same is true for final demand for electricity versus petroleum products. In addition, both the transport sector and final demand need to spend more on products of " 21 Motor vehicles, trailers \& semi-trailers", because these need in total $4 \%$ more inputs, which are assumed to have an impact of $4 \%$ on prices, i.e. the price of industry 21 increases by $4 \%$ :

$$
\Delta p_{21}=4 \%
$$

This translates via the real input coefficient and the relative prices into an increase of $4 \%$ of the nominal input coefficient

$$
A N_{21,33}=\left(p_{21} / p_{33}\right) A R_{21,33}
$$

when assuming that the price of industry 33 does not change. These coefficient changes are applied to the following countries (representing about two thirds of total global new cars in use), assuming that these are the countries in which the electric cars are used: EU28, all non-EU OECD countries (except Chile), Mainland China, Hong Kong and Taiwan.

The domestic road transport industry (33 Land transport; transport via pipelines) uses less gasoline and diesel from industry " 8 Coke, refined petroleum products and nuclear fuel" and more inputs from the electricity industry "26 Production, collection and distribution of electricity". Here, we can assume that mostly imports from the petroleum products industry are affected, as it is the interest to first use domestically produced petroleum products, to decrease the import dependency. The increase in electricity consumption, however, can be assumed to primarily affect the domestic industry (if enough electricity is available). Thus, while the import coefficient of industry "8 Coke, refined petroleum products and nuclear fuel" decreases the domestic input coefficient of "26 Production, collection and distribution of electricity" increases for industry "33 Land transport; transport via pipelines". The change of the input coefficient of industry 21 is explained in the previous paragraph. The same changes apply to the final demand structure.

In addition, not only does the input structure of industry 33 (land transport) change, but also the emission coefficient, because it uses less petroleum products and thus creates fewer direct emissions from energy use. This will be reflected in the energy balance where the use of energy carrier "Oil products" decreases, while the use of energy carrier "Electricity" increases. The emission intensity of industry 33 will therefore decrease depending on the share of ICE vehicles in the total fleet. In the case of a complete switch to electric vehicles, the direct emission intensity decreases to zero.

\section{Results and Discussion}

For two industries with high direct and embedded carbon emissions that are identified in 3.1, changes in consumption-based emissions are calculated top-down and bottom-up as two case studies. Top-down analysis makes use of the MRIO model GRAM. For each bottom-up analysis specific LCA analysis is applied.

\subsection{Selection of Industries for Further Analysis}

To get a first impression on which groups of goods and services consumed in the EU have high embedded emissions, the MRIO analysis was applied. The upper part in Figure 2 displays the amount of carbon embedded in the consumption of final goods in the EU28 in 2010 for the 48 industries modelled in the MRIO GRAM. According to input-output methodology, each industry produces a homogeneous product. The industries are ranked according to the import content of embedded carbon emissions. Those industries that will be analyzed in more detail below are marked with red arrows. Note that the numbers presented here exclude residential emissions and emissions from private road transport, which are estimated to be about $50 \%$ of total transport emissions. These emissions were not considered in the system since they are direct domestic emissions not embedded in traded products. 


\section{Industries according to embedded emissions}

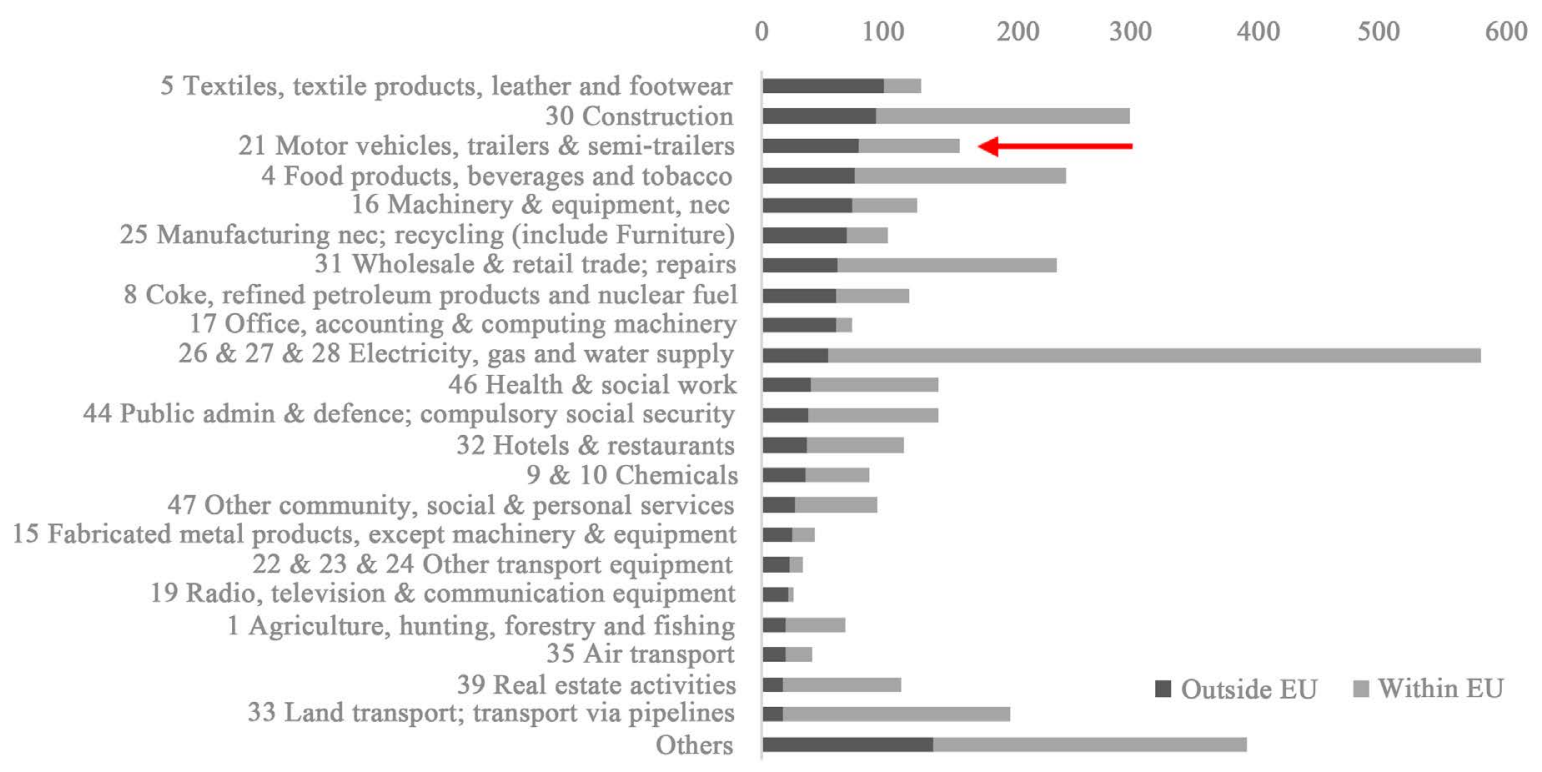

\section{Industries emitting $\mathrm{CO}_{2}$ emissions consumed in the EU28}

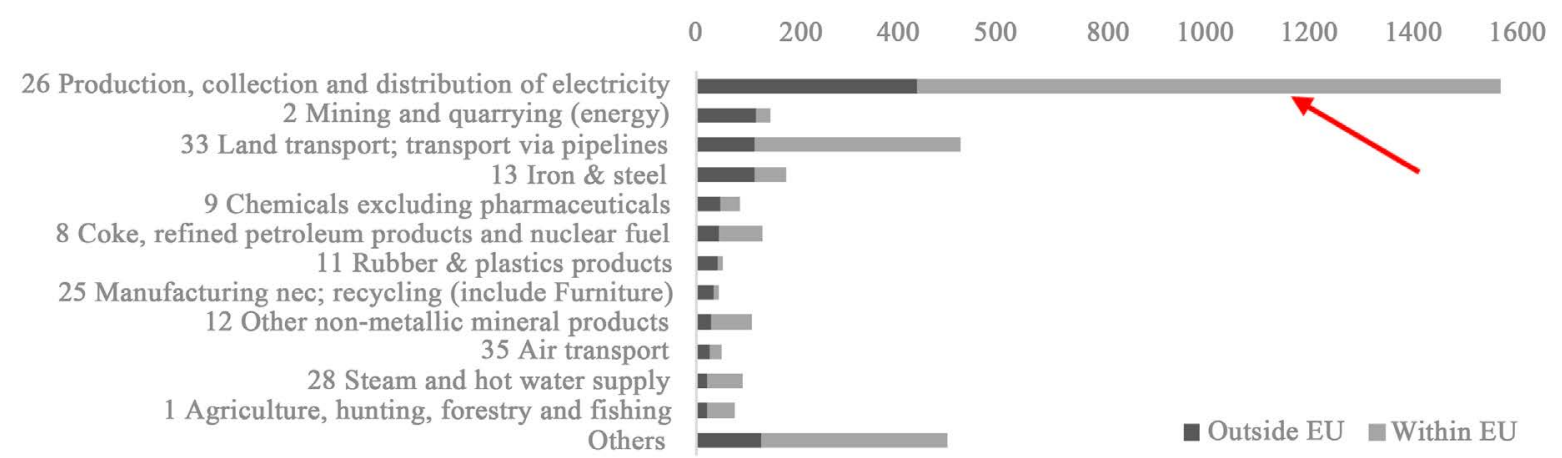

Figure 2. $\mathrm{CO}_{2}$ emissions embedded in goods consumed in the EU28 in 2010 in $\mathrm{Mt} \mathrm{CO}_{2}$ according to origin (emitted within EU28 or outside EU28).

The carbon embedded in goods and services finally consumed within the EU28 countries in 2010 differed significantly between the industries. This is mainly due to large differences in underlying final demand for these products. While " 5 textiles, textile products, leather and footwear" (upmost red arrow) is an industry that mostly produces final products, the basic metals industry ("13 Iron and steel" and "14 Non-ferrous metals", included in "others") mainly produce intermediate products, and so the final demand for products from these industries is very small. Furthermore, the share of embedded carbon imports differs across industries. While for products from the textiles industry, less than a quarter of the embedded emissions occurred within the territory of the EU28 countries (and thus more than three quarters are emitted elsewhere in the world), the share of embedded carbon imports in total embedded carbon for products from the food industry (4) is only one third.

The lower part of Figure 2 shows the industries in which emissions occur during the production of goods and services that are eventually consumed in the EU28. The industries are again ranked according to emissions produced outside the EU. The industry to which more than $40 \%$ of the total and more than one third of imported consumption-based emissions can be traced back is Production, collection and distribution of electricity (26). Ranked second is Mining and quarrying of energy resources (10\% of imported, but only $4 \%$ of total consumption-based emissions), closely followed by Land transport (33) (10\% of imported, 15\% of total) and Iron and steel (13) (10\% of imported, $5 \%$ of total). The mining and quarrying of energy resources industry extracts the 
resources used for electricity production and the iron and steel industry produces a major part of the materials used for motor vehicles production.

On the basis of these results and a stakeholder workshop, the case studies chosen concern vehicles industry, as well as electricity production, as indicated by the red arrows in the figures. For the example of motor vehicles, the comparison of the upper and lower part show how important they are from a final demand perspective while being insignificant from a production perspective.

\subsection{EU's $\mathrm{CO}_{2}$ in Cars Regulation}

The $\mathrm{CO}_{2}$ in Cars Regulation [38] is a phased set of mandatory emissions reduction targets applied to all new passenger vehicles entering the European marketplace. These fleet-wide targets represent the cornerstone of the EU's strategy to reduce the emissions of cars bought in Europe. This case study investigated the potential impact on both in-use and embedded emissions of the policy in relation to the $130 \mathrm{~g} / \mathrm{km}$ and $95 \mathrm{~g} / \mathrm{km}$ targets set for vehicles in 2015 and 2021 respectively.

\subsubsection{The Bottom-Up Analysis}

The bottom-up approach undertaken in this case study aimed to include the full life cycle impacts of the production and use of passenger cars split into two categories of:

- In use emissions-The $\mathrm{CO}_{2}$ emissions associated with operation of the vehicles i.e. emissions related to fuel use.

- Embodied emissions-The $\mathrm{CO}_{2}$ emissions embedded in the material extraction, manufacturing of and disposal of vehicles.

Both European and international data was required to develop the models on which to base the analysis. These included TREMOVE stock model data for the passenger car sector, forecast of vehicle efficiency standards scenarios to 2030 and LCA data to provide embedded emissions for vehicles technologies forecast to 2030 [39].

For the purposes of the investigation, scenarios were chosen envisioning four possible market pathways (see descriptions in key of Figure 3). The scenarios were based upon extensive previous research, including that underpinning the "EU Transport GHG: Routes to 2050 II” project report published in July 2012 [40].

This data was then applied in the context of the scenarios utilizing the Ricardo AEA SULTAN transport model, which allowed calculation of fleet emissions based on key criteria of vehicle numbers (by age, and technologies) and forecast vehicle efficiency standards as defined by the technical scenarios developed.

The results of this analysis for 2030 are summarized in Figure 3. This indicated a large potential reduction in the in-use emissions resulting from passenger cars combined with a marginal increase in the embodied emissions required to manufacture more technologically advanced vehicles, such as battery electric and hydrogen fuel cell vehicles.

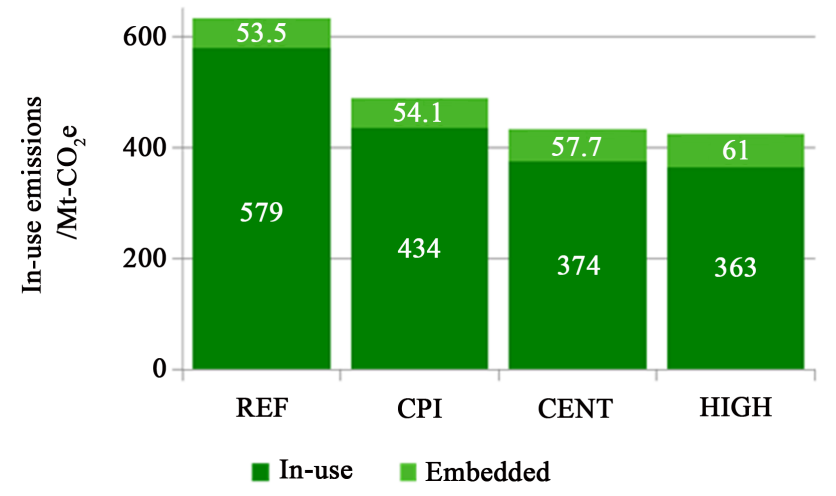

Figure 3. Summary of modelled emissions outputs for the EU scenario's developed in 2030. REF-Baseline scenario with no further change from 2013; CPI-Current policy initiative forecast emissions based on current policies; CENT - Central policy initiative includes additional central policy initiatives; HIGH-Ambitious scenario in which more regimented policy results in greater savings. 


\subsubsection{The Top-Down Analysis}

Changes implemented in the MRIO GRAM are described in Section 2.4. Note that the changes as such are comparable to the assumptions in the bottom-up case study. However, the top-down analysis takes into account all direct and indirect global effects. In addition, the analysis is a "static" scenario based on the model structure of 2010, not accounting for changing intermediate demand structures and changing trade patterns until 2030.

The results of the $\mathrm{EU} \mathrm{CO}_{2}$ in Cars Regulation scenario (corresponding to the CPI scenario in the bottom-up analysis) take into account both the changes in the production structure (see Figure 1) and the changes in final demand, that are consistently implemented in the model. Figure 4 shows that in the CPI scenario total consumption-based emissions in the EU are reduced by $0.4 \%$ (rightmost grey bar, left vertical axis). Emissions within the EU are reduced by $0.6 \%$ and emissions embedded in imports are reduced by $0.1 \%$ (not displayed in graph). The negative green bars indicate reduced in-use emissions in the transport sector, the positive blue bars show higher carbon intensity of new car technologies. The grey colored bars (sum of green and blue) show the percentage change in emissions originating from the named countries/regions. The highest negative change in emissions occurs in Norway, while emissions in India, China, South Africa and the ASEAN countries increase. This is due to the relatively carbon intensive electricity production and the use of more electricity by the transport sector and private car usage.

\subsubsection{Bottom-Up versus Top-Down Analysis}

The top-down findings show a shift in emissions in car life cycles: emissions embedded in demand for land transport activities (in-use emissions, EU28-green bar) are reduced, while emissions embedded in final demand for motor vehicles (car production phase, embedded emissions) increase. However, the scale of the changes differs. This can be explained by the fact that passenger cars (which are the subject of the bottom-up analysis) represent only a small share of industry "21 Motor vehicles, trailers and semi-trailers" and a fraction of the transport mode used in "33 Land transport; transport via pipelines". This is where one of the disadvantages of the aggregation of goods and services in MRIO analysis becomes apparent. As well as motor vehicles, 33 includes "freight rail transport", "freight transport by road and removal services", "passenger rail transport, interurban", "other passenger land transport" and "transport via pipelines". The bottom-up analysis only considers passenger transport, which is only a fraction of the sub-category "other passenger land transport" of industry 33. The percentage changes visible in the top-down analysis at the industry level therefore should be smaller and are smaller than those apparent from the bottom-up analysis.

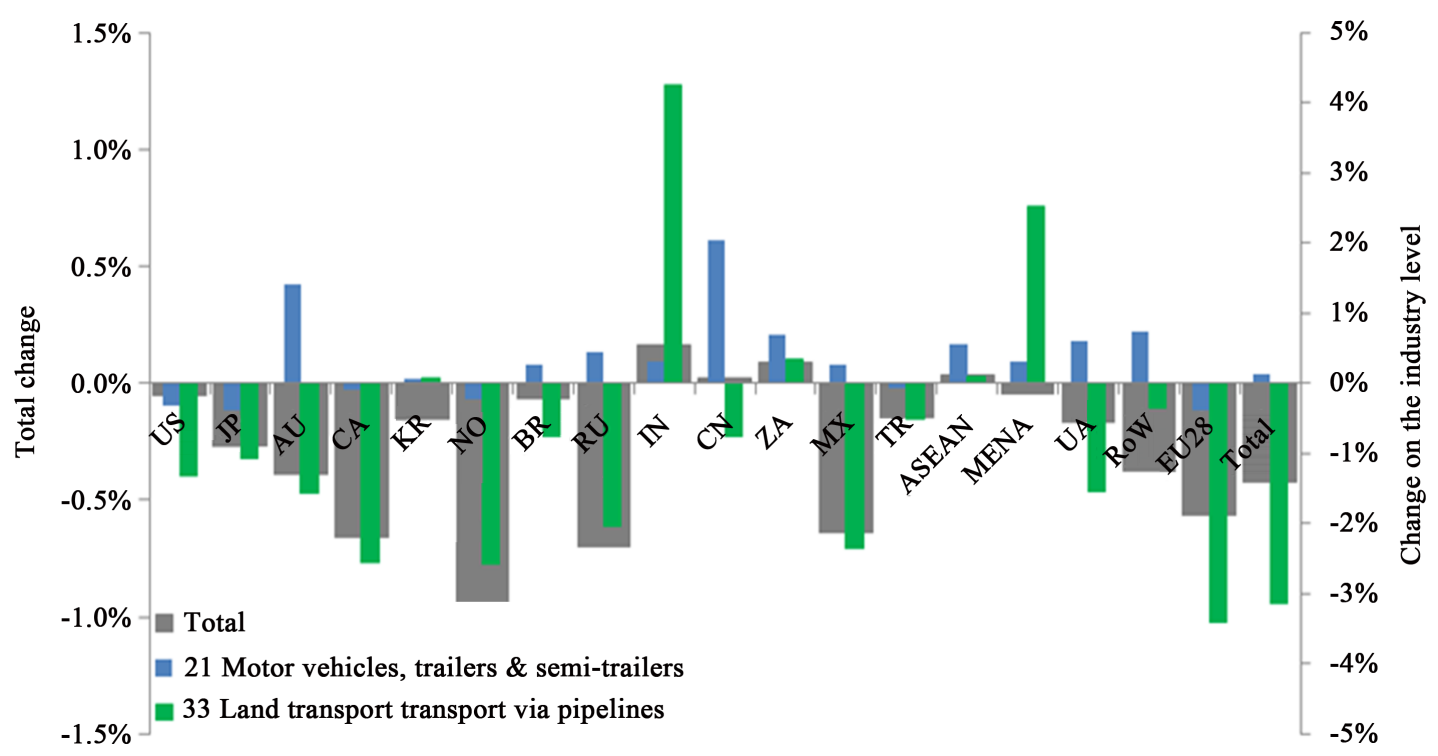

Figure 4. Percentage change in emissions embedded in total final demand of EU (grey) and of the final demand of EU for goods from industries 21 (blue) and 33 (green) by origin. Changes in EU consumption-based emissions (total EU demand-grey, EU demand for motor vehicles-blue, EU demand for transport services—green) originating in the countries displayed on the horizontal axis. 
Both bottom-up and top-down analyses suggest that the production of new car technologies is more emissions intensive than the production of cars with internal combustion engines. The total effect on emissions depends on the emission intensity of production of electricity needed for using the cars. If the additional electricity needed in Europe is provided by carbon-free renewable energy, emissions within the EU decrease. In case of India or China, where current electricity production is very carbon intensive, total emissions (embedded plus in-use) may even rise when switching from internal combustion engines to the new technologies in these countries.

\subsection{South Africa Renewable Energy Producer Procurement}

South Africa's electricity mix is dominated by coal (94\%) and only entails $1 \%$ renewables including hydro ([41]). Therefore, in 2011, the government of South Africa introduced the Integrated Resource Plan (IRP) of installing 17.8 GW renewables by 2030 and the Renewable Energy Independent Power Producer Procurement Programme (REIPPPP), which aimed at procuring renewable energy installations of 3725 MW by 2016, and an additional 3200 MW by 2020. Using both a bottom-up analysis and a top-down MRIO approach, this case study looks at three scenarios for the impact of these plans on the carbon embedded in aluminium produced in South Africa and consumed in the EU:

- Reference scenario: This is a projection of emissions assuming that no climate change mitigation actions have taken place since 2010.

- REIPPPP and IRP renewables + additional measures scenario: Assuming all the renewable targets under the REIPPPP policy and the 2020-2030 planned IRP renewables are implemented. The IRP scenario includes renewable energy, plus other low carbon technologies included in the IRP plan.

- REIPPPP and IRP renewables-only scenario: The impact of just the renewable technologies introduced due to the REIPPPP and IRP.

The case of aluminium is chosen, as production is very electricity intensive (and carbon intensive in the case of South Africa) to highlight the impact of this process for EU consumption-based emissions.

\subsubsection{Bottom-Up Analysis}

The first step in the bottom-up analysis was to determine the effect that the REIPPPP policy and the IRP 20102030 had on South Africa's electricity generation capacity (see Figure 5). Both policy scenarios show that as
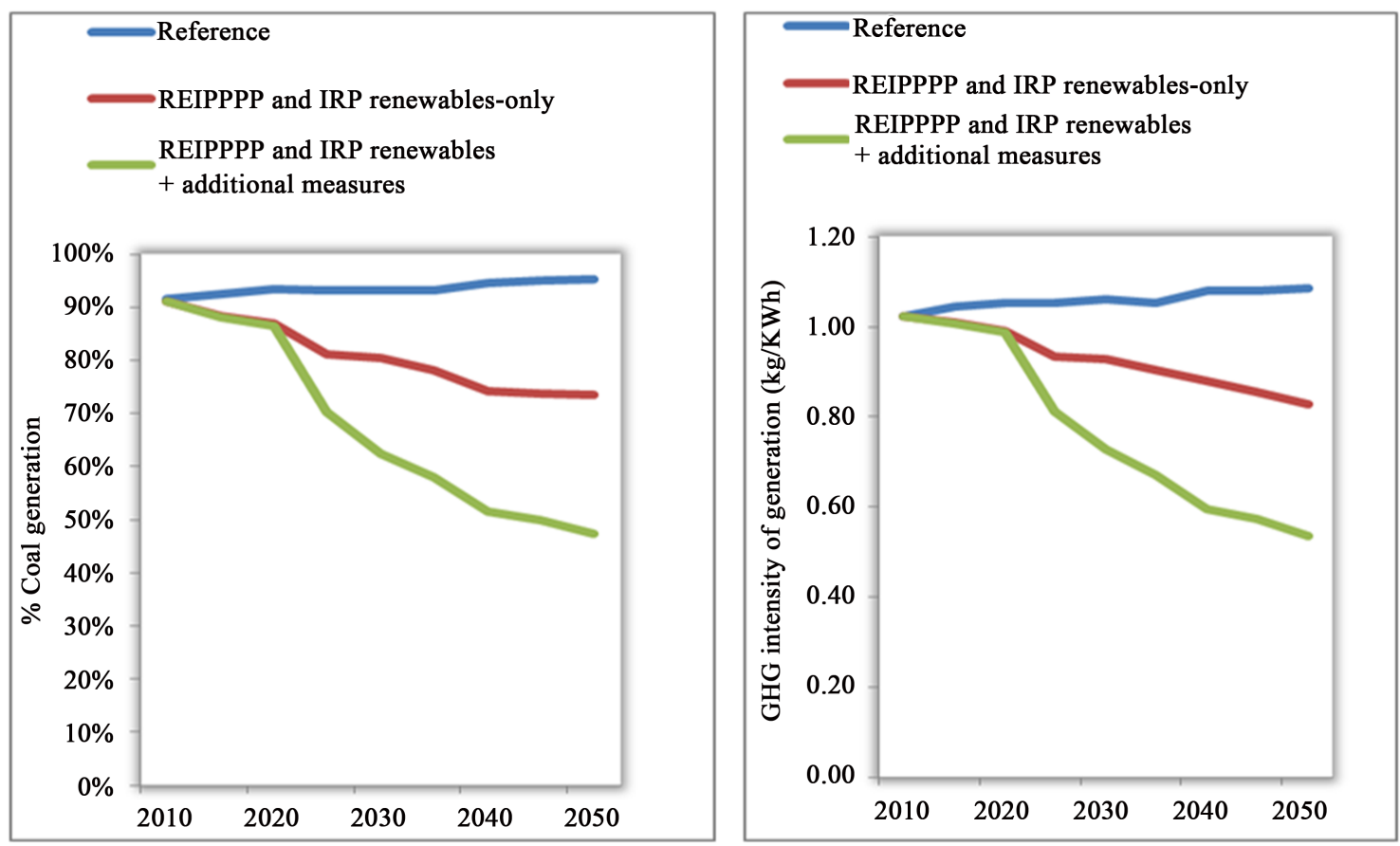

Figure 5. Change in the percentage of coal generation (on the left) and change in GHG intensity (on the right), over time. 
the percentage of renewable energy increases, the coal generation decreases and so does the GHG intensity of the electricity mix. It was found that, by 2020, the REIPPPP policy should result in approximately $16 \%$ of the South African electricity generation capacity being made up of renewable energy, compared to an estimate of just over 4\%, if no additional renewable energy policy were in place. By 2050, the renewable capacity could reach nearly $35 \%$. This significantly reduces the usage of coal for electricity production, enabling a decoupling of resource use and production.

The above will have an effect on the GHG emissions in the aluminium production process and the embodied energy of aluminium produced in South Africa. The next step in the analysis was to quantify this effect. It was calculated that, by 2020, the emission intensity in the production process, for both new scenarios, could reduce by an estimated $6 \%$ and by 2050 , the emission intensity of production could decrease by half for the renewables + additional measures and a quarter for the renewables only scenario.

The aluminium produced in South Africa had a $\mathrm{CO}_{2}$ intensity of approximately $15 \mathrm{t} \mathrm{CO}_{2} / \mathrm{t}$ in 2010 , which is at the high end of global spectrum, which ranges from 3 t CO $2 / t$ to $17 \mathrm{t} \mathrm{CO}_{2} / \mathrm{t}$ [42]. This figure only account for the electricity used in the production of aluminium so would be a little higher if other energy sources were taken into account. Both of the policy scenarios cause a reduction of the embedded emission of aluminium over time:

- The greatest reduction in emissions is observed in the REIPPPP and IRP renewables + additional measures scenario, where emissions could reduce to 10 t $\mathrm{CO}_{2} / \mathrm{t}$ in 2030 and $7 \mathrm{t} \mathrm{CO}_{2} / \mathrm{t}$ in 2050 .

- The renewables only policy could result in a reduction of the CO2 intensity to 13 t $\mathrm{CO}_{2} / \mathrm{t}$ in 2030 and $11 \mathrm{t}$ $\mathrm{CO}_{2} / \mathrm{t}$ in 2050 .

The final step was to assess the embodied emissions of aluminium imported into the EU. The results show that there will be a marked reduction in emissions imported into the EU over time as a result of the REIPPPP and IRP policy, with and without the additional measures. By 2050, emissions could fall from about 2 million tonnes $\mathrm{CO}_{2} \mathrm{e}$ per annum in the reference policy to about 1.5 million tonnes $\mathrm{CO}_{2} \mathrm{e}$ in the policy only scenario and to about 1 million tonnes $\mathrm{CO}_{2} \mathrm{e}$ in the policy + scenario. This is a $24 \%$ reduction in EU carbon emissions from the consumption of South African aluminium in the renewable only policy, and a 51\% saving in the REIPPPP and IRP renewables + additional measures scenario.

These results show that policies that increase renewable energy capacity in South Africa are expected to have a significant impact on the emissions intensity of the electricity generated. This in turn will reduce the embedded emissions of aluminium produced in South Africa, and its benchmark emissions performance in comparison to other global suppliers.

\subsubsection{Top-Down Analysis}

MRIO analysis calculates impacts of changes in the South African power mix on consumption-based emissions in the EU. The anticipated deployment of renewable electricity generation technologies in South Africa affects two variables in the top-down model GRAM: intermediate input structure $A$ and emission intensity $e$ for South Africa. The emission intensity $e$ of electricity sector changes, while the emission intensity of the non-ferrous metals industry, which includes aluminium, remains the same, because, according to the energy balance, the non-ferrous metals industry does not use any fossil fuels directly. The intermediate input structure $A$ of industry 26 Production, collection and distribution of electricity changes as fewer fossil fuels are used. The inputs of coal (industry 2 mining and quarrying (energy)) are reduced.

The changes implemented here correspond to the changes displayed in the bottom-up case for 2030 for the two scenarios. In the scenario without additional measures, the coal inputs into the electricity generation sector are reduced by $11.6 \%$, which corresponds to a drop in the emissions intensity of $9.3 \%$. For the scenario with additional measures the implemented changes are $-31.4 \%$ and $-29.0 \%$ respectively.

These changes result in a reduction of $7 \%$ of production-based emissions in South Africa for the first scenario and of 20\% when additional measures are implemented. In both cases, the emissions embedded in goods consumed in South Africa decrease relatively more than emissions embedded in exports. This is because most of the electricity is indeed consumed within South Africa.

The effects on consumption-based emissions of the EU28 countries are small, but visible, and are presented in Figure 6. Emissions embedded in imports for EU28 final demand decrease by $0.1 \%$ and $0.5 \%$ for the two scenarios respectively (see Column [2]). When only considering emissions embedded in imports that originate from South Africa, the reductions are 6\% and 19\%, respectively for the two scenarios (Column [3]). 


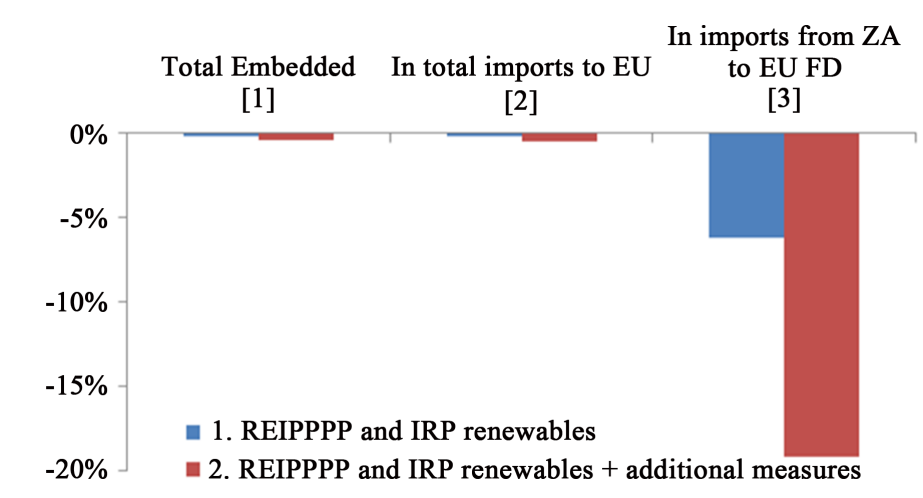

Figure 6. Effect of South African renewables policies on emissions embedded in EU consumption in 2030.

\subsubsection{Bottom-Up versus Top-Down Analysis}

This analysis shows that policies that increase renewable energy capacity in South Africa are expected to have a significant impact on the emissions intensity of the electricity generated. This in turn will reduce the embedded emissions of aluminium produced in South Africa, and its benchmark emissions performance in comparison to other global suppliers. The total amount of EU consumption-based emissions saved due to electricity generation from renewables in South Africa is about ten times as high as those related to aluminium.

Aluminium is mainly an intermediate product, i.e. it is not itself a final good, but rather embedded in a large variety of final goods, e.g. bikes, computers, cars, buildings, etc. Calculated from the bottom-up, the emissions embedded in aluminium imports from South Africa therefore represent the emissions embedded in intermediate goods and not in final goods consumed in the EU. This shows one of the most significant differences between the top-down and bottom-up approach: system boundaries. While the top-down approach can capture the entire effect on European consumption-based emissions of the South African renewable energy policy, the bottom-up approach, only looks one of the most energy intensive products, which is mainly an intermediate product for final demand goods.

The difference between the results of the bottom-up and the top-down analysis stem from two sources: First, the top-down results consider direct (emissions embedded in goods directly imported from South Africa into the $\mathrm{EU}$ ) and indirect emissions embedded in final demand, i.e. also the emissions that occurred during production of intermediate goods in South Africa that were then further processed somewhere in the world, before they were imported into the EU. Second, the non-ferrous metals sector encompasses other metals than aluminium as well. In addition, the top-down analysis includes the total impact of the South African Renewables Initiative, not only the effect on emissions embedded in aluminium and it includes the effect on emissions embedded in final demand and not only in the intermediate product aluminium.

\section{Conclusions}

The above analysis shows that different policies aimed at reducing carbon emissions can be analyzed from a consumption perspective with both a bottom-up and a top-down approach. The bottom-up approach entails specific life cycle assessment, while the top-down approach uses multi-regional input-output analysis. Both methodologies are applied to analyze two policies, the $\mathrm{EU} \mathrm{CO}_{2}$ in Cars Regulation and the South African renewable energy plan, with regard to their effect on carbon emissions embedded in goods and services consumed in the EU. The South Africa case study explicitly looks into the policy impact on aluminium production and related energy consumption.

For the two policies, the bottom-up and the top-down approaches give similar results (same sign and scope), but not the same numbers. This is due to very different level of aggregation. While the bottom-up analysis looks specifically at cars for the $\mathrm{CO}_{2}$ in Cars Regulation, the top-down approach only analyzes the industry "motor vehicles, trailers and semi-trailers", of which "cars" are only one part. Thus, in this case, the results from the bottom-up analysis are more precise than those from the top-down analysis.

In contrast, for the renewable energy plan in South Africa, the top-down approach is able to capture all effects on carbon embedded in EU consumption, while the bottom-up analysis is only able to look at one product at a 
time and cannot distinguish, of all the aluminium imported from South Africa into the EU, between that which remains in the EU and that which is further processed and exported again. The top-down analysis takes into account all direct and indirect trade flows from South Africa to the EU and, therefore, the entire effect of the reduction in carbon emissions from electricity production in South Africa on carbon embedded in products consumed in the EU. Further, using the MRIO approach is able to identify where in the world the emissions occur that are embedded in EU consumption. Presented case studies demonstrate the international dimension of carbon policies. Future design of national policies will have to take these interlinkages into account.

Both approaches are able to link local consumption to global impacts. The results and the comparison of the results from the two approaches show that some policies and their effects on embedded emission in EU are easier to model and analyze using the bottom-up approach, e.g. $\mathrm{CO}_{2}$ in cars, while for others, e.g. South African renewable energy, the top-down approach is more suitable. Thus, bottom-up and top-down approaches can and need to be applied to different policies and are generally complementary. To summarize, bottom-up LCA and top-down MRIO modelling can both be used to estimate the effects of policies on embedded carbon emissions. LCA appears to be more precise when product-specific policies are being assessed. MRIO works better for wider ranging policies, where multiple products are affected.

However, the findings are still limited to just two case studies. Further research is needed to look into other policies as well as additional countries and to elaborate more general findings for the appropriate use and combination of LCA and MRIO. This can either produce and then build on additional case studies or start from a methodological point of view. Different types of analysis will have to be evaluated and structured concerning their application. Hybrid approaches, which partly combine LCA and MRIO and could also focus on one of the two methods, have also to be taken into account. They may turn out to be more appropriate for specific policy evaluation.

Though focusing on carbon, both case studies look into resource use and policy and could be extended from carbon emissions and underlying fossil fuel consumption to other emissions and resources. Experiences made for the combination of LCA and MRIO approaches to analysis carbon emissions can help to apply both instruments to global resource use and resource policies. While MRIO is able to analyze the role of consumption for global resource use, LCA and MRIO should be combined to better understand impacts of mainly national resource policies.

\section{Acknowledgements}

The research presented in this paper is part of the project "Consumption based approaches to climate mitigation: data collection, measurement methods and model analysis" for DG CLIMA. The information and views set out in this paper are those of the authors and do not necessarily reflect the official opinion of the Commission. The Commission does not guarantee the accuracy of the data included in this paper. Neither the Commission nor any person acting on the Commission's behalf may be held responsible for the use that may be made of the information contained therein.

The authors would like to thank Manfred Lenzen for sharing his valuable knowledge about existing literature about hybrid analysis.

We thank our colleagues for contributing comments and suggestions for this research paper.

\section{References}

[1] Peters, G. and Solli, C. (2010) Global Carbon Footprints: Methods and Import/Export Corrected Results from the Nordic Countries in Global Carbon Footprint Studies. TemaNord. Nordic Council of Ministers, Copenhagen, Denmark. http://dx.doi.org/10.6027/tn2010-592

[2] Lenzen, M. (2001) Errors in Conventional and Input-Output-Based Life Cycle Inventories. Journal of Industrial Ecology, 4, 127-148. http://dx.doi.org/10.1162/10881980052541981

[3] Moran, D., McBain, D., Kanemoto, K., Lenzen, M. and Geschke, A. (2015) Global Supply Chains of Coltan: A Hybrid Life Cycle Assessment Study Using a Social Indicator. Journal of Industrial Ecology, 19, 357-365. http://dx.doi.org/10.1111/jiec.12206

[4] Moran, D., Petersone, M. and Verones, F. (2016) On the Suitability of Input-Output Analysis for Calculating Product-Specific Biodiversity Footprints. Ecological Indicators, 60, 192-201. http://dx.doi.org/10.1016/j.ecolind.2015.06.015 
[5] Schoer, K., Wood, R., Arto, I. and Weinzettel, J. (2013) Estimating Raw Material Equivalents on a Macro-Level: Comparison of Multi-Regional Input-Output Analysis and Hybrid LCI-IO. Environmental Science \& Technology, 47, 14282-14289. http://dx.doi.org/10.1021/es404166f

[6] Weinzettel, J., Steen-Olsen, K., Hertwich, E.G., Borucke, M. and Galli, A. (2014) Ecological Footprint of Nations: Comparison of Process Analysis, and Standard and Hybrid Multiregional Input-Output Analysis. Ecological Economics, 101, 115-126. http://dx.doi.org/10.1016/j.ecolecon.2014.02.020

[7] Finnveden, G., Hauschild, M.Z., Ekvall, T., Guinée, J., Heijungs, R., Hellweg, S., Koehler, A., Pennington, D. and Suh, S. (2009) Recent Developments in Life Cycle Assessment. Journal of Environmental Management, 91, 1-21. http://dx.doi.org/10.1016/j.jenvman.2009.06.018

[8] International Organisation for Standardisation (1998) ISO 14044 Environmental Management—Life Cycle AssessmentPrinciples and Framework. International Organisation for Standardisation, Geneva.

[9] Hertwich, E.G., Gibon, T., Bouman, E.A., Arvesen, A., Suh, S., Heath, G.A., Bergesen, J.D., Ramirez, A., Vega, M.I. and Shi, L. (2015) Integrated Life-Cycle Assessment of Electricity-Supply Scenarios Confirms Global Environmental Benefit of Low-Carbon Technologies. PNAS (Proceedings of the National Academy of Sciences of the United States of America), 112, 6277-6282. http://dx.doi.org/10.1073/pnas.1312753111

[10] Wiedmann, T., Wilting, H.C., Lenzen, M., Lutter, S. and Palm, V. (2011b) Quo Vadis MRIO? Methodological, Data and Institutional Requirements for Multi-Region Input-Output Analysis. Ecological Economics, 70, 1937-1945. http://dx.doi.org/10.1016/j.ecolecon.2011.06.014

[11] Wiedmann, T. and Barret, J. (2013) Current and Future Policy Applications of MRIO Research. Chapter 27. In: Murray, J. and Lenzen, M., Eds., The Sustainability Practitioner's Guide to Multi-Regional Input-Output Analysis, Common Ground Publishing, Illinois, 267-272.

[12] Peters, G.P., Andrew, R. and Lennox, J. (2011) Constructing an Environmentally-Extended Multi-Regional InputOutput Table Using the GTAP Database. Economic Systems Research, 23, 131-152. http://dx.doi.org/10.1080/09535314.2011.563234

[13] Lenzen, M., Moran, D., Kanemoto, K. and Geschke, A. (2013) Building EORA: A Global Multi-Region Input-Output Database at High Country and Sector Resolution. Economic Systems Research, 25, 20-49. http://dx.doi.org/10.1080/09535314.2013.769938

[14] Nakano, S., Okamura, A., Sakurai, N., Suzuki, M., Tojo, Y. and Yamano, N. (2009) The Measurement of $\mathrm{CO}_{2}$ Embo- $^{-}$ diments in International Trade: Evidence from the Harmonised Input-Output and Bilateral Trade Database. Organisation for Economic Co-Operation and Development (OECD). http://dx.doi.org/10.1787/227026518048

[15] Wiebe, K.S., Bruckner, M., Giljum, S. and Lutz, C. (2012a) Calculating Energy-Related $\mathrm{CO}_{2}$ Emissions Embodied in International Trade Using a Global Input-Output Model. Economic Systems Research, 24, 113-139. http://dx.doi.org/10.1080/09535314.2011.643293

[16] Wiebe, K.S., Bruckner, M., Giljum, S., Lutz, C. and Polzin, C. (2012b) Carbon and Materials Embodied in the International Trade of Emerging Economies: A Multiregional Input-Output Assessment of Trends between 1995 and 2005. Journal of Industrial Ecology, 16, 636-646. http://dx.doi.org/10.1111/j.1530-9290.2012.00504.X

[17] Tukker, A., Poliakov, E., Heijungs, R., Hawkins, T., Neuwahl, F., Rueda-Cantuche, J.M., Giljum, S., Moll, S., Oosterhaven, J. and Bouwmeester, M. (2009) Towards a Global Multi-Regional Environmentally Extended Input-Output Database. Ecological Economics, 68, 1928-1937. http://dx.doi.org/10.1016/j.ecolecon.2008.11.010

[18] Timmer, M. (2012) The World Input-Output Database (WIOD): Contents, Sources and Methods. Working Paper Number 10, April 2012, Version 0.9.

[19] Tukker, A. and Dietzenbacher, E. (2013) Global Multiregional Input-Output Frameworks: An Introduction and Outlook. Economic Systems Research, 25, 1-19. http://dx.doi.org/10.1080/09535314.2012.761179

[20] Peters, G.P., Davis, S.J. and Andrew, R. (2012) A Synthesis of Carbon in International Trade. Biogeosciences, 9, 3247-3276. http://dx.doi.org/10.5194/bg-9-3247-2012

[21] Lenzen, M., Kanemoto, K., Moran, D. and Geschke, A. (2012) Mapping the Structure of the World Economy. Environmental Science \& Technology, 46, 8374-8381. http://dx.doi.org/10.1021/es300171x

[22] Suh, S. and Nakamura, S. (2007) Five Years in the Area of Input-Output and Hybrid LCA. The International Journal of Life Cycle Assessment, 12, 351. http://dx.doi.org/10.1007/s11367-007-0358-9

[23] Wiedmann, T.O., Suh, S., Feng, K., Lenzen, M., Acquaye, A., Scott, K. and Barrett, J.R. (2011a) Application of Hybrid Life Cycle Approaches to Emerging Energy Technologies-The Case of Wind Power in the UK. Environmental Science \& Technology, 45, 5900-5907. http://dx.doi.org/10.1021/es2007287

[24] Bullard, C.W., Penner, P.S. and Pilati, D.A. (1978) Net Energy Analysis: Handbook for Combining Process and InputOutput Analysis. Resources and Energy, 1, 267-313. http://dx.doi.org/10.1016/0165-0572(78)90008-7

[25] Suh, S. and Huppes, G. (2005) Methods for Life Cycle Inventory of a Product. Journal of Cleaner Production, 13, 687- 
697. http://dx.doi.org/10.1016/j.jclepro.2003.04.001

[26] Crawford, R.H. (2008) Validation of a Hybrid Life-Cycle Inventory Analysis Method. Journal of Environmental Management, 88, 496-506. http://dx.doi.org/10.1016/j.jenvman.2007.03.024

[27] Lenzen, M. and Crawford, R. (2009) The Path Exchange Method for Hybrid LCA. Environmental Science \& Technology, 43, 8251-8256. http://dx.doi.org/10.1021/es902090z

[28] Feng, K., Chapagain, A., Suh, S., Pfister, S. and Hubacek, K. (2011) Comparison of Bottom-Up and Top-Down Approaches to Calculating the Water Footprints of Nations. Economic Systems Research, 23, 371-385. http://dx.doi.org/10.1080/09535314.2011.638276

[29] Treloar, G.J. (1997) Extracting Embodied Energy Paths from Input-Output Tables: Towards an Input-Output-Based Hybrid Energy Analysis Method. Economic Systems Research, 9, 375-391. http://dx.doi.org/10.1080/09535319700000032

[30] Lenzen, M. and Dey, C. (2000) Truncation Error in Embodied Energy Analyses of Basic Iron and Steel Products. Energy, 25, 577-585. http://dx.doi.org/10.1016/S0360-5442(99)00088-2

[31] Nakamura, S., Murakami, S., Nakajima, K. and Nagasaka, T. (2008) Hybrid Input-Output Approach to Metal Production and Its Application to the Introduction of Lead-Free Solders. Environmental Science \& Technology, 42, 38433848. http://dx.doi.org/10.1021/es702647b

[32] Liu, C.-H., Lenzen, M. and Murray, J. (2012) A Disaggregated Emissions Inventory for Taiwan with Uses in Hybrid Input-Output Life Cycle Analysis (IO-LCA). Natural Resources Forum, 36, 123-141. http://dx.doi.org/10.1111/j.1477-8947.2012.01439.x

[33] Wiebe, K.S. (2016) The Impact of Renewable Energy Diffusion on European Consumption-Based Emissions. Economic Systems Research, 28, 1-18. http://dx.doi.org/10.1080/09535314.2015.1113936

[34] Großmann, A., Lehr, U., Wiebe, K.S. and Wolter, M.I. (2013) Progress Report 5a-Modelling the Effects of the Energy Transition in Austria. Assessment of the Economic and Environmental Effects. http://www.umweltbuero-klagenfurt.at/feasiblefutures/wp-content/uploads/Progress_Report_5A_Feasible_Futures_Gro ssmann_et_al_final.pdf

[35] Sugawara, T. and Shibusawa, H. (2010) Evaluating the Economic Impacts of the Technological Innovation in the Motor Vehicle Industry: The Input-Output Approach. 50th European Congress of the Regional Science Association International, 19-23 August 2010, Jönköping.

[36] Barthel, K., Böhler-Baedecker, S., Bormann, R., Dispan, J., Fink, P., Koska, T., Meißner, H.R. and Pronold, F. (2010) Zukunft der deutschen Automobilindustrie. WISO Diskurs, Dezember 2010, Friedrich-Ebert-Stiftung, Bonn.

[37] Hou, et al. (2006) A Study on the Technology Information Which Contributes the Comprehensive Economic, Energy and Environmental Analyses. The Institute of Energy Economics, Japan, 33-49. (In Japanese)

[38] European Commission (2014) $\mathrm{CO}_{2}$ in Cars Regulation. http://ec.europa.eu/clima/policies/transport/vehicles/cars/index en.htm

[39] Ricardo-AEA (2013) Current and Future Lifecycle Emissions of Key ‘Low Carbon’ Technologies and Alternatives. Final Report for the Committee on Climate Change.

http://www.theccc.org.uk/wp-content/uploads/2013/04/Ricardo-AEA-lifecycle-emissions-low-carbon-technologies-Ap ril-2013.pdf

[40] Hill, N., Brannigan, C., Smokers, R., Schroten, A., van Essen, H. and Skinner, I. (2012) Developing a Better Understanding of the Secondary Impacts and Key Sensitivities for the Decarbonisation of the EU's Transport Sector by 2050. http://www.eutransportghg2050.eu/cms/reports/

[41] IEA (2012) Energy Balances of OECD Countries 2009-2010. IEA, Paris.

[42] Carbon Trust (2011a) International Carbon Flows-Aluminium (CTC790).

https://www.carbontrust.com/media/38366/ctc790-international-carbon-flows_-aluminium.pdf 